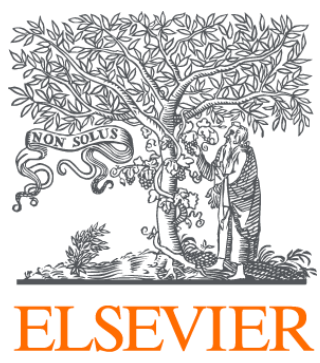

Since January 2020 Elsevier has created a COVID-19 resource centre with free information in English and Mandarin on the novel coronavirus COVID-

19. The COVID-19 resource centre is hosted on Elsevier Connect, the company's public news and information website.

Elsevier hereby grants permission to make all its COVID-19-related research that is available on the COVID-19 resource centre - including this research content - immediately available in PubMed Central and other publicly funded repositories, such as the WHO COVID database with rights for unrestricted research re-use and analyses in any form or by any means with acknowledgement of the original source. These permissions are granted for free by Elsevier for as long as the COVID-19 resource centre remains active. 


\section{Treatment of Community-Acquired Pneumonia in Immunocompromised Adults}

\section{A Consensus Statement Regarding Initial Strategies}

Julio A. Ramirez, MD; Daniel M. Musher, MD; Scott E. Evans, MD; Charles Dela Cruz, MD; Kristina A. Crothers, MD; Chadi A. Hage, MD; Stefano Aliberti, MD; Antonio Anzueto, MD; Francisco Arancibia, MD; Forest Arnold, DO;

Elie Azoulay, MD; Francesco Blasi, MD; Jose Bordon, MD; Steven Burdette, MD; Bin Cao, MD; Rodrigo Cavallazzi, MD; James Chalmers, MD; Patrick Charles, MD; Jean Chastre, MD; Yann-Erick Claessens, MD; Nathan Dean, MD; Xavier Duval, MD; Muriel Fartoukh, MD; Charles Feldman, MD; Thomas File, MD; Filipe Froes, MD; Stephen Furmanek, MPH; Martin Gnoni, MD; Gustavo Lopardo, MD; Carlos Luna, MD; Takaya Maruyama, MD; Rosario Menendez, MD; Mark Metersky, MD; Donna Mildvan, MD; Eric Mortensen, MD; Michael S. Niederman, MD; Mathias Pletz, MD; Jordi Rello, MD; Marcos I. Restrepo, MD; Yuichiro Shindo, MD; Antoni Torres, MD; Grant Waterer, MD; Brandon Webb, MD; Tobias Welte, MD; Martin Witzenrath, MD; and Richard Wunderink, MD

BACKGROUND: Community-acquired pneumonia (CAP) guidelines have improved the treatment and outcomes of patients with CAP, primarily by standardization of initial empirical therapy. But current society-published guidelines exclude immunocompromised patients. RESEARCH QUESTION: There is no consensus regarding the initial treatment of immunocompromised patients with suspected CAP.

STUDY DESIGN AND METHODS: This consensus document was created by a multidisciplinary panel of 45 physicians with experience in the treatment of CAP in immunocompromised patients. The Delphi survey methodology was used to reach consensus.

RESULTS: The panel focused on 21 questions addressing initial management strategies. The panel achieved consensus in defining the population, site of care, likely pathogens, microbiologic workup, general principles of empirical therapy, and empirical therapy for specific pathogens. INTERPRETATION: This document offers general suggestions for the initial treatment of the immunocompromised patient who arrives at the hospital with pneumonia.

CHEST 2020; 158(5):1896-1911

KEY WORDS: community-acquired pneumonia; immunocompromised; pneumonia

FOR EDITORIAL COMMENT, SEE PAGE 1802; FOR RELATED ARTICLE, SEE PAGE 1912

ABBREVIATIONS: CAP = community-acquired pneumonia; $\mathrm{CMV}=$ cytomegalovirus; $\mathrm{MDR}=$ multiple drug resistant; $\mathrm{MRSA}=$ methicillinresistant Staphylococcus aureus; NTM = nontuberculous mycobacteria; PCP = Pneumocystis jirovecii pneumonia; TMP-SMX = trimethoprimsulfamethoxazole; TNF = tumor necrosis factor

AFFILIATIONS: From the Division of Infectious Diseases (Drs Ramirez, Arnold, and Gnoni, and Mr Furmanek), University of Louisville, Louisville, KY; the Baylor College of Medicine and Michael E. DeBakey VA Medical Center (Dr Musher), Houston, TX; the Department of Pulmonary Medicine (Dr Evans), University of Texas MD Anderson Cancer Center, Houston, TX; Pulmonary, Critical Care and Sleep Medicine (Dr Dela Cruz), Yale University, New Haven, CT; the
Veterans Puget Sound Health Care System (Dr Crothers), University of Washington, Seattle WA; the Thoracic Transplant Program (Dr Hage), Indiana University, Indianapolis, IN; the Department of Pathophysiology and Transplantation (Drs Aliberti and Blasi), University of Milan, and Fondazione IRCCS Cà Granda Ospedale Maggiore Policlinico, Respiratory Unit and Cystic Fibrosis Adult Center, Milan, Italy; the South Texas Veterans Health Care System (Drs Anzueto and Restrepo), Audie L. Murphy Memorial Veterans Hospital, and University of Texas Health, San Antonio, TX; the Pneumology Service (Dr Arancibia), Instituto Nacional del Tórax and Clínica Santa María, Santiago de Chile, Chile; the Medical ICU (Dr Azoulay), Saint-Louis Teaching Hospital, Assistance Publique-Hôpitaux de Paris 
(APHP), Paris, France; the Section of Infectious Diseases (Dr Bordon), Providence Health Center, Washington, DC; the Wright State University Boonshoft School of Medicine (Dr Burdette), Dayton, OH; the Department of Pulmonary and Critical Care Medicine (Dr Cao), Center of Respiratory Medicine, National Clinical Research Center for Respiratory Diseases, China-Japan Friendship Hospital, Beijing, China; the Division of Pulmonary, Critical Care, and Sleep Disorders Medicine (Dr Cavallazzi), University of Louisville, Louisville, KY; the Scottish Centre for Respiratory Research (Dr Chalmers), School of Medicine, Ninewells Hospital and Medical School, Dundee, UK; the Department of Infectious Diseases (Dr Charles), Austin Health and Department of Medicine, University of Melbourne, Australia; the Service de Médecine Intensive-Réanimation (Dr Chastre), Hôpital La Pitié-Salpêtrière, Sorbonne Université, APHP, Paris, France; the Department of Emergency Medicine (Dr Claessens), Centre Hospitalier Princesse Grace, Monaco; the Intermountain Medical Center and the University of Utah (Dr Dean), Salt Lake City, UT; the UMR 1137, IAME, INSERM (Dr Duval), and CIC 1425, Hôpital Bichat-Claude Bernard, APHP, Paris, France; the Service de Médecine Intensive Réanimation (Dr Fartoukh), Hôpital Tenon, APHP, and APHP, Sorbonne Université, Faculté de Médecine Sorbonne Université, Paris, France; the Department of Internal Medicine (Dr Feldman), Faculty of Health Sciences, University of the Witwatersrand, Johannesburg, South Africa; the Infectious Disease Section (Dr File), Northeast Ohio Medical University and Infectious Disease Division, Summa Health, Akron, OH; the ICU, Chest Department (Dr Froes), Hospital Pulido Valente-Centro Hospitalar Universitário Lisboa Norte, Lisbon, Portugal; the Fundación del Centro de Estudios Infectológicos (Dr Lopardo), Buenos Aires, Argentina; the Pulmonary Diseases Division (Dr Luna), Universidad de Buenos Aires, Buenos Aires, Argentina; the Department of Respiratory Medicine (Dr Maruyama), National Hospital Organization Mie National Hospital, Tsu, Japan; the Pneumology Department (Dr Menendez), La Fe University and Polytechnic Hospital, La Fe Health Research Institute, Valencia, Spain; the Division of Pulmonary, Critical Care and Sleep Medicine and Center for Bronchiectasis Care (Dr Metersky), University of Connecticut Health, Farmington, CT; the Icahn School of Medicine at Mount Sinai (Dr Mildvan), New York, NY; the Department of Medicine (Dr Mortensen), University of Connecticut Health Center, Farmington, CT; Pulmonary and Critical Care (Dr Niederman), New York Presbyterian/ Weill Cornell Medical Center and Weill Cornell Medical College, New York, NY; the Institute for Infectious Diseases and Infection Control (Dr Pletz), Jena University Hospital, Jena, Germany; the Centro de Investigacion Biomedica en Red de Enfermedades Respiratorias (Dr Rello), Instituto de Salud Carlos III, and Infections Area, Vall d'Hebron Institute of Research, Barcelona, Spain; the Department of Respiratory Medicine (Dr Shindo), Nagoya University Graduate School of Medicine, Nagoya, Japan; the Servei de Pneumologia (Dr Torres), Hospital Clinic, Universitat de Barcelona. Barcelona, CIBERES, Spain; the School of Medicine (Dr Waterer), University of Western Australia, Perth, Australia; the Division of Infectious Diseases and Clinical Epidemiology (Dr Webb), Intermountain Healthcare, Salt Lake City, UT and Division of Infectious Diseases and Geographic Medicine, Stanford Medicine, Palo Alto, CA; the German Center for Lung Research (Dr Welte), Biomedical Research in Endstage and Obstructive Lung Disease Hannover (BREATH) Clinic of Pneumology, Hannover Medical School, Hannover, Germany; the Division of Pulmonary Inflammation and Department of Infectious Diseases and Respiratory Medicine (Dr Witzenrath), Charité-Universitätsmedizin Berlin, Freie Universität Berlin, Humboldt-Universität zu Berlin, and Berlin Institute of Health, Berlin, Germany; and Pulmonary and Critical Care (Dr Wunderink), Northwestern University Feinberg School of Medicine, Chicago, IL.

FUNDING/SUPPORT: Sponsored by the International Respiratory Infection Society.

CORRESPONDENCE TO: Julio A. Ramirez, MD, Division of Infectious Diseases, University of Louisville, 501 E Broadway, Ste 100, Louisville, KY 40202; e-mail: j.ramirez@louisville.edu

Copyright $(\subset) 2020$ Published by Elsevier Inc under license from the American College of Chest Physicians.

DOI: https://doi.org/10.1016/j.chest.2020.05.598
Guidelines for the treatment of patients with community-acquired pneumonia (CAP) have been published by medical societies from several countries. These guidelines have improved the treatment and outcomes of patients with CAP, primarily by standardization of initial empirical therapy. But current society-published CAP guidelines exclude immunocompromised patients. ${ }^{1-3}$

Immunocompromised patients have been excluded from guidelines because of their need for complex, often individualized, treatment, the expanded spectrum of potential pathogens, and their exclusion from the large prospective studies of antibiotic efficacy used to support guideline recommendations.

The number of immunocompromised people at risk for CAP is increasing, due to (1) longer survival of patients with cancer, and recipients of organ transplants; (2) better recognition of immunocompromising conditions; (3) additional risk groups, such as those receiving novel immune-modulating therapies for nonmalignant diseases; and (4) approval of newer immunomodulatory agents. It is estimated that $3 \%$ of the adult population of the United States is immunosuppressed. ${ }^{4}$

Immunocompromising conditions are present in approximately $20 \%$ to $30 \%$ of hospitalized patients with CAP. $^{5-7}$

Frequently, the initial treatment of pneumonia in immunocompromised patients may not occur in specialized tertiary care centers with advanced expertise in their care. Rather, immunocompromised patients with symptoms of lower respiratory tract infection often present first to general hospitals to be treated by ED physicians, internists, or hospitalists. These general conditions are identical to those motivating the initial impetus for guidelines to treat CAP; namely, the frequency of the condition and the presentation of patients in many different health-care settings throughout the community.

Early and adequate empirical treatment of CAP in the general population is associated with decreased morbidity and mortality, and the authors attempt here to facilitate application of these same principles to patients at high risk of CAP-related complications due to preexisting immune dysfunction. The approaches suggested in this document are based on an extensive review of the literature and on the collective experience of the authors. A challenge in reviewing the CAP literature on the immunocompromised host is that most publications evaluate outcomes of antimicrobial therapy 
for patients in whom the pathogen causing CAP has been identified. No large, prospective clinical studies comparing different empirical therapies in immunocompromised patients exist.

Susceptibility to specific infections varies widely in immunocompromised patients and depends both on the degree of immune suppression and the components of the immune system that are affected by the underlying disease and/or medical therapy. In this document we attempt to develop a unifying approach to simplify a very complex topic, involving a heterogeneous population. The objective of this document is to suggest an approach to the initial treatment of immunocompromised patients with suspected CAP.

\section{Methods}

The Delphi survey methodology was used to reach consensus. After a full review of the English literature on the topic of treatment of CAP in the immunocompromised patient, the Delphi questions used in the survey were developed (Table 1). The following 5-point Likert scale was used to evaluate agreement or disagreement with each proposed answer: strongly disagree (1), disagree (2), neutral (3), agree (4), strongly agree (5). It was considered that a consensus was reached once more than $75 \%$ of participants agreed or strongly agreed with a particular suggestion.

In each round of the Delphi survey, questions regarding the treatment of CAP in the immunocompromised patient were submitted to all 45 participants in the consensus process. To anonymously record participant responses and comments, a survey was developed using Research Electronic Data Capture (REDCap), which allowed participants to answer with their level of agreement with the suggestion, and to write specific comments regarding the management suggested by the group. After each round, all responses were summarized and an anonymized summary of all the comments was produced and sent to each participant. Participants had the opportunity to revise their earlier answers, considering the anonymized replies of other members of the panel.

After the participants answered the third round of all questions, the range of the answers decreased significantly and it was considered that the group had reached consensus. At that point, a prefinal manuscript was created and submitted to all participants for final comments and agreement ratings. After the final comments were incorporated, the manuscript was produced. Further details regarding the Delphi survey methodology and rounds are to be found in e-Appendix 1 in the online article.

\section{Statistical Analysis}

At each round of the survey, the mean and SD of agreement based on the Likert scale for each question were calculated. To evaluate the level of agreement or disagreement for each question in a manner that incorporated both the mean and SD, a $t$-statistic for each question was calculated. The $t$-statistic was used to identify which questions had the least amount of agreement or the most controversy. Agreement was visualized by bar charts, and final agreement was reported as the percentage of participants who responded as Agree or Strongly Agree.

\section{Results}

\section{A. Definition of Population}

\section{Question 1: Which patients with CAP should be considered immunocompromised?}

We suggest that patients with CAP should be considered to be immunocompromised if they have an underlying disease or medical treatment that alters the immune system to the point that they are at elevated risk of pneumonia not only by common organisms but also by uncommon avirulent or opportunistic organisms.

No consensus exists regarding which patients should be formally considered immunocompromised. Our pragmatic approach is to consider patients to be immunocompromised if they are at elevated risk of pneumonia not only by common organisms but also by uncommon avirulent or opportunistic organisms. Several practical aspects of meeting this definition include the need for comprehensive microbiologic testing, the need to alter empirical antimicrobial therapy, and the need for adjunctive therapy. Even using this more restrictive definition, medical advances supporting longer survival of patients with serious conditions and an expanding armamentarium of biological agents result in expanding populations of at-risk individuals. Using this approach, the most common acquired conditions that qualify a patient as being immunocompromised are a malignancy that suppresses immune responses (such as lymphoma or leukemia) and advanced HIV infection (CD4 T-lymphocyte count $<200$ cells/ $\mu \mathrm{L}$ ). The most frequent treatments that qualify a patient as being immunocompromised include glucocorticoids, therapies that suppress B-cell or T-cell responses, chemotherapy for malignancy that causes neutropenia, conventional disease-modifying antirheumatic drugs, and biological agents used to treat a broad range of rheumatologic, dermatologic, GI, and autoimmune diseases. Notably, some agents (eg, ibrutinib, alemtuzumab, or fludarabine) have persistent immunosuppressive effects, long after active treatment is discontinued. Conditions indicating that patients are immunocompromised are listed in Table 2. ${ }^{8-13}$

Most patients who develop CAP have one or more comorbid condition(s) that increase their susceptibility 
TABLE 1] Questions Addressing Initial Treatment Strategies for Immunocompromised Adults With CommunityAcquired Pneumonia

\section{A. Definition of Population}

Question 1: Which patients with CAP should be considered immunocompromised?

\section{B. Site of Care}

Question 2: Which immunocompromised patients with CAP should be admitted to the hospital?

\section{Likely Pathogens}

Question 3: What pathogens should be considered "core respiratory pathogens" in patients with CAP who are immunocompromised?

Question 4: What pathogens should be considered beyond the core respiratory pathogens in patients with CAP who are immunocompromised?

\section{Microbiological Workup}

Question 5: What microbiologic studies should be done in hospitalized patients with CAP who are immunocompromised?

Question 6: When should bronchoscopy with bronchoalveolar lavage be performed in hospitalized patients with CAP who are immunocompromised?

Question 7: What microbiologic studies can be done with BAL fluid from hospitalized patients with CAP who are immunocompromised?

\section{E. Empirical Therapy: General Principles}

Question 8: What empirical therapy should be started in hospitalized patients with CAP who are immunocompromised?

Question 9: In which patients with CAP who are immunocompromised should empirical therapy be extended beyond the core respiratory pathogens?

Question 10: What role does the severity of pneumonia play in the selection of initial empirical therapy?

\section{F. Empirical Therapy: Specific Pathogens}

Question 11: In which immunocompromised patients should the initial empirical therapy be extended to cover the possibility of CAP due to MRSA?

Question 12: In which immunocompromised patients should the initial empirical therapy be extended to cover the possibility of CAP due to drug-resistant gram-negative bacilli, including Pseudomonas aeruginosa?

Question 13: In which immunocompromised patients should the initial empirical therapy be extended to cover the possibility of CAP due to multidrug-resistant (MDR) gram-negative bacilli?

Question 14: In which immunocompromised patients should the initial empirical therapy be extended to cover the possibility of CAP due to Pneumocystis jirovecii pneumonia (PCP)?

Question 15: In which immunocompromised patients should the initial empirical therapy be extended to cover the possibility of CAP due to Aspergillus?

Question 16: In which immunocompromised patients should the initial empirical therapy be extended to cover the possibility of CAP due to Mucorales?

Question 17: In which immunocompromised patients should the initial empirical therapy be extended to cover the possibility of CAP due to Nocardia?

Question 18: In which immunocompromised patients should the initial empirical therapy be extended to cover the possibility of CAP due to varicella-zoster virus?

Question 19: In which immunocompromised patients should the initial empirical therapy be extended to cover the possibility of CAP due to cytomegalovirus?

Question 20: In which immunocompromised patients should the initial empirical therapy be extended to cover the possibility of CAP due to Mycobacterium tuberculosis?

Question 21: In which immunocompromised patients should the initial empirical therapy be extended to cover the possibility of CAP due to parasites?

$\mathrm{CAP}=$ community-acquired pneumonia; MRSA = methicillin-resistant Staphylococcus aureus.

to infection. From this perspective, patients with common comorbid conditions such as diabetes, chronic lung disease, liver disease, kidney disease, or even those who are elderly and frail, can be considered relatively immunocompromised. However, patients with this degree of immune dysfunction are typically infected with the same spectrum of organisms that cause CAP in younger or healthier adults, and their treatment is covered in the current CAP guidelines. 
TABLE 2 ] Patient Conditions Qualifying Patients as Immunocompromised

\begin{tabular}{|c|c|}
\hline Patient Condition & References \\
\hline Primary immune deficiency diseases & $\ldots$ \\
\hline $\begin{array}{l}\text { Active malignancy or malignancy within } 1 \text { y of CAP, excluding patients with localized skin cancers or early-stage } \\
\text { cancers (eg, stage } 1 \text { lung cancer) }\end{array}$ & $\ldots$ \\
\hline Receiving cancer chemotherapy & $\ldots$ \\
\hline HIV infection with a CD4 T-lymphocyte count $<200$ cells $/ \mu \mathrm{L}$ or percentage $<14 \%{ }^{\text {a }}$ & 8 \\
\hline Solid organ transplantation & $\ldots$ \\
\hline Hematopoietic stem cell transplantation & $\ldots$ \\
\hline $\begin{array}{l}\text { Receiving corticosteroid therapy with a dose } \geq 20 \mathrm{mg} \text { prednisone or equivalent daily for } \geq 14 \mathrm{~d} \text { or a cumulative } \\
\text { dose }>600 \mathrm{mg} \text { of prednisone }\end{array}$ & 9,10 \\
\hline Receiving biological immune modulators ${ }^{c}$ & 11,12 \\
\hline $\begin{array}{l}\text { Receiving disease-modifying antirheumatic drugs or other immunosuppressive drugs (eg, cyclosporin, } \\
\text { cyclophosphamide, hydroxychloroquine, methotrexate) }\end{array}$ & 13 \\
\hline
\end{tabular}

See Table 1 legend for expansion of abbreviation.

aThe association of HIV disease and CAP can be categorized in three levels: Level 1: Patients with a CD4 T-lymphocyte count > 500 cells/ $\mu$ L. These patients are not at increased risk of CAP. Level 2: Patients with a CD4 T-lymphocyte count between 500 and 200 cells/ $\mu \mathrm{L}$. These patients are at increased risk of CAP, but are not considered immunocompromised because the etiologic agents are the core CAP pathogens such as Streptococcus pneumoniae. Level 3: Patients with a CD4 T-lymphocyte count < 200 cells/ $\mu \mathrm{L}$. These patients are at risk for CAP due to opportunistic pathogens such as Pneumocystis jirovecii. They are considered immunocompromised patients with CAP.

${ }^{b}$ In the case of patients taking steroid and who have CAP, both the daily dose and the cumulative dose of steroids should be considered. The association with CAP can be define in three levels: Level 1: Doses $\leq 10 \mathrm{mg}$ of prednisone per day and a cumulative dose of less than 600 mg of prednisone or equivalent. These patients are not at increased risk of CAP. Level 2: Doses 10 to $\leq 20 \mathrm{mg}$ of prednisone per day with a cumulative dose greater than 600 mg of prednisone or equivalent at the time of the CAP episode. These patients are at increased risk of CAP, but are not considered immunocompromised because the etiologic agents are the core CAP pathogens such as Streptococcus pneumoniae. Level 3: Doses $\geq 20$ mg or more of prednisone per day with a cumulative dose greater than $600 \mathrm{mg}$ of prednisone or equivalent at the time of the CAP episode. These patients are at risk for CAP due to opportunistic pathogens such as Pneumocystis jirovecii. They are considered immunocompromised patients with CAP. Because of the cumulative dose of at least 600 mg, these patients need to have received steroid therapy for at least 3 to 4 wk to be considered as fulfilling this condition.

'These drugs are used to treat a wide array of inflammatory conditions and have multiple immunologic targets. The diverse effects of these drugs include interfering with cell signaling, inhibiting cytokine function, interrupting innate immunity, depleting B cells, or inhibiting T-cell activation. Specific discussion of these drugs in detail is beyond the scope of this article. However, nearly all immunomodulators carry some risk of infection. Because these immunomodulating agents affect different components of the immune system, the risk for specific infections varies with the target of the immunomodulator.

\section{B. Site of Care}

\section{Question 2: Which immunocompromised patients with CAP should be admitted to the hospital?}

We suggest that the decision for hospitalization should be based on clinical judgment having a low threshold for hospital admission.

In patients with CAP who are not immunocompromised, the admission decision is based on clinical judgment and can be supplemented by using validated severity scores such as the Pneumonia Severity Index or the CRB-65/CURB-65. Hospitalization of immunocompromised patients with CAP is based primarily on clinical judgment, considering that CAP severity scores have not been well validated in immunocompromised patients. ${ }^{14-16}$ Because immunosuppressive drugs are known to modulate the inflammatory response, the typical signs and symptoms of CAP may be attenuated in these patients. The blunted inflammatory response may not produce a clear infiltrate on chest radiography. A CT scan of the chest will allow better definition of the extent of pulmonary infiltrate as well as better recognition of complications of pneumonia such as abscesses or pleural effusions. This information, gained by CT imaging of the chest, may help in the decision regarding hospitalization. Hypoxia is a particularly useful criterion to define site of care. In nonimmunocompromised patients with CAP, blood oxygen saturation $<92 \%$ is considered an appropriate threshold for hospital admission. ${ }^{17}$

Immunocompromised patients may appear stable at the time of the initial evaluation but may deteriorate rapidly, progressing in a few hours from moderately severe pneumonia to severe pneumonia in need of intensive care. Also, the increased range of potential infecting agents renders selection of any empirical regimen much more challenging, often requiring parenteral agents. Therefore, our suggestion is for a low threshold for hospitalization. If the patient is considered sufficiently stable for outpatient care, mechanisms for close follow- 
up and rapid reentry to inpatient health care should be available.

\section{Likely Pathogens}

Question 3: What pathogens should be considered "core respiratory pathogens" in patients with CAP who are immunocompromised?

We suggest that the list of core respiratory pathogens able to cause CAP in the immunocompromised patient should be the same as those for the nonimmunocompromised.

Immunocompromised patients are susceptible to infection with the same respiratory viruses and bacteria that cause CAP in nonimmunocompromised patients. We call these "core respiratory pathogens." Common respiratory viral pathogens that cause mild upper respiratory tract infections in healthy adults can lead to severe lower respiratory tract infections in

immunocompromised patients. Table 3 lists the primary groups of core respiratory pathogens that can cause CAP in immunocompromised patients. $5,6,18$

Question 4: What pathogens should be considered beyond the core respiratory pathogens in patients with CAP who are immunocompromised?

We suggest to focus attention on respiratory pathogens that may cause CAP in the immunocompromised patient and for which antimicrobial therapy is available.

When considering likely etiologies of CAP beyond the core respiratory pathogens, it is important to focus attention on organisms that are amenable to antimicrobial treatment. Common respiratory pathogens that (1) may cause CAP in the immunocompromised host and (2) for which antimicrobial therapy is available are listed in Table 4. Different types of immunocompromising conditions will predispose to different types of etiologic agents. A description of specific immune deficiencies and the associated respiratory pathogens are depicted in Table 5.

Initial empirical therapy active against these respiratory pathogens may be necessary only in selected patients presenting with specific epidemiologic, clinical, or immunologic risk factors for infection due to a particular pathogen. These risk factors and the specific pathogens that are involved are discussed below.

\section{Microbiological Workup}

Question 5: What microbiologic studies should be done in hospitalized patients with CAP who are immunocompromised?

We suggest a comprehensive microbiological workup with the goal to perform pathogen-directed therapy and deescalation of therapy.

A critical aspect of the treatment of these patients is an initial microbiologic workup coupled with empirical therapy, followed by a deescalation to therapy directed to the causative pathogen. Deescalation of therapy is important because continuing broad-spectrum therapy for the full duration of therapy is associated with selection of multidrug-resistant organisms, increased risk of toxicity, drug-drug interactions, and impaired antimicrobial stewardship for the entire community. As the primary way to perform deescalation therapy is by knowing which pathogen is causing the pneumonia, a comprehensive microbiologic workup is critically

TABLE 3 ] Core Respiratory Pathogens That May Cause Community-Acquired Pneumonia in the Immunocompromised Patient

\begin{tabular}{|c|c|c|c|}
\hline Gram-Positive Bacteria & Gram-Negative Bacteria & "Atypical" Bacteria & Respiratory Viruses \\
\hline $\begin{array}{r}\text { Streptococcus } \\
\text { pneumoniae }\end{array}$ & Haemophilus influenzae & $\begin{array}{l}\text { Legionella } \\
\text { pneumophila }\end{array}$ & Influenza virus \\
\hline $\begin{array}{l}\text { Staphylococcus aureus } \\
\text { (MSSA) }\end{array}$ & Moraxella catarrhalis & $\begin{array}{c}\text { Chlamydophila } \\
\text { pneumoniae }\end{array}$ & Parainfluenza virus \\
\hline $\begin{array}{l}\text { Streptococcus } \\
\text { pyogenes }\end{array}$ & $\begin{array}{l}\text { Enterobacteriaceae (eg, Klebsiella species, } \\
\text { Escherichia coli) }\end{array}$ & $\begin{array}{l}\text { Mycoplasma } \\
\text { pneumoniae }\end{array}$ & Coronavirus \\
\hline \multirow[t]{4}{*}{ Other streptococci } & & Coxiella burnetii & $\begin{array}{l}\text { Respiratory } \\
\text { syncytial virus }\end{array}$ \\
\hline & & & Rhinovirus \\
\hline & & & Adenovirus \\
\hline & & & $\begin{array}{l}\text { Human } \\
\text { metapneumovirus }\end{array}$ \\
\hline
\end{tabular}

MSSA = methicillin-susceptible Staphylococcus aureus. 
TABLE 4 ] Common Respiratory Pathogens in Addition to Core Respiratory Pathogens ${ }^{a}$ That Can Cause Community-Acquired Pneumonia in the Immunocompromised Patient and for Which Antimicrobial Therapy Is Available

\begin{tabular}{|c|c|c|c|c|}
\hline Bacteria & Mycobacteria & Viruses & Fungi & Parasites \\
\hline $\begin{array}{l}\text { Enterobacteriaceae (including those } \\
\text { producing } \mathrm{ESBL} \text {, and also CRE) }\end{array}$ & $\begin{array}{l}\text { Mycobacterium } \\
\text { TB }\end{array}$ & Cytomegalovirus & $\begin{array}{l}\text { Pneumocystis } \\
\text { jirovecii }\end{array}$ & $\begin{array}{l}\text { Toxoplasma } \\
\text { gondii }\end{array}$ \\
\hline $\begin{array}{l}\text { Nonfermenting gram-negative bacilli (eg, } \\
\text { Pseudomonas or Acinetobacter) }\end{array}$ & $\begin{array}{r}\text { Nontuberculous } \\
\text { mycobacteria }\end{array}$ & $\begin{array}{l}\text { Herpes simplex } \\
\text { virus }\end{array}$ & $\begin{array}{l}\text { Aspergillus } \\
\text { species }\end{array}$ & $\begin{array}{l}\text { Strongyloides } \\
\text { stercoralis }\end{array}$ \\
\hline MRSA & & $\begin{array}{l}\text { Varicella-zoster } \\
\text { virus }\end{array}$ & $\begin{array}{l}\text { Mucorales } \\
\text { species }\end{array}$ & \\
\hline Nocardia species & & & $\begin{array}{l}\text { Histoplasma } \\
\text { species }\end{array}$ & \\
\hline \multirow[t]{3}{*}{ Rhodococcus equi } & & & $\begin{array}{l}\text { Cryptococcus } \\
\text { species }\end{array}$ & \\
\hline & & & $\begin{array}{l}\text { Blastomyces } \\
\text { species }\end{array}$ & \\
\hline & & & $\begin{array}{l}\text { Coccidioides } \\
\text { species }\end{array}$ & \\
\hline
\end{tabular}

$\mathrm{CRE}=$ carbapenemase-producing Enterobacteriaceae; ESBL = extended-spectrum $\beta$-lactamase. See Table 1 legend for expansion of other abbreviation. ${ }^{a}$ As described in Table 3.

important. Another reason to perform broad microbiologic studies is that treatment of opportunistic pathogens is complex and often complicated by toxicities and drug-drug interactions.

The extent of the microbiologic workup should be individualized, considering the presence of risk factors and likely organisms, as well as local capabilities. The field of diagnostic microbiologic techniques has experienced significant progress. The development of rapid diagnostic tests using new molecular techniques and sophisticated new laboratory methods, such as matrix-assisted laser desorption ionization-time of flight (MALDI-TOF) mass spectrometry, is reshaping the clinical microbiology laboratory as well as our ability to identify etiologic agents of CAP in immunocompromised patients. ${ }^{19}$ A list of common microbiologic studies with relevant clinical considerations is depicted in Table $6{ }^{20-29}$

Question 6: When should bronchoscopy with bronchoalveolar lavage be performed in hospitalized patients with CAP who are immunocompromised?

We suggest that the decision to perform a bronchoscopy or bronchoalveolar lavage should be individualized.

Bronchoscopy with BAL will be useful even in a clinically unstable patient if the patient is at risk for infection with multiple opportunistic pathogens and an experienced team is available to perform the procedure.
Preferably, bronchoscopy with BAL should be done early so that initial empirical therapy does not alter the culture results. If the bronchoscopy can be done promptly, a short delay before initiating antibiotic therapy may be acceptable, given improved culture yield. In general, the more immunocompromised the host, the greater the potential benefit of performing bronchoscopy with BAL.

If the etiology of CAP may be defined on the basis of initial radiography and point-of-care diagnostic testing, the small, but nevertheless clear risk associated with bronchoscopy with BAL may outweigh the benefit. $^{30}$

Question 7: What microbiologic studies can be done with $B A L$ fluid from hospitalized patients with CAP who are immunocompromised?

We suggest that microbiological studies in bronchoalveolar lavage should be ordered according to the presence of risk factors for particular pathogens.

In some institutions a fixed panel of tests is routinely performed on BAL from immunocompromised patients with CAP. In other institutions, the tests are ordered considering the presence of clinical, radiographic, and immunologic risk factors for specific organisms.

Table $7^{31-35}$ lists microbiologic studies that can be done on BAL or tissue from a transbronchial lung biopsy together with relevant clinical considerations. 
TABLE 5 ] Specific Immune Deficiencies and Associated Respiratory Pathogens

\begin{tabular}{|c|c|}
\hline Specific Immune Deficiency & Unique Respiratory Pathogen Associations \\
\hline Neutropenia & $\begin{array}{l}\text { Pseudomonas aeruginosa, Stenotrophomonas maltophilia, } \\
\text { Enterobacteriaceae, Streptococcus mitis, Staphylococcus } \\
\text { aureus, Nocardia species, Aspergillus and other hyaline } \\
\text { molds (Scedosporium, Fusarium), yeast-like fungi } \\
\text { (Trichosporon), Mucorales species, dimorphic fungi }\end{array}$ \\
\hline AIDS & $\begin{array}{l}\text { Pneumocystis jirovecii, Streptococcus pneumoniae, } \\
\text { Mycobacterium TB, M. avium-intracellulare complex, and } \\
\text { other nontuberculous mycobacteria, Histoplasma } \\
\text { capsulatum, Coccidioides, Bartonella, Rhodococcus, } \\
\text { Toxoplasma gondii, Cryptococcus neoformans, } \\
\text { Cryptosporidium, Nocardia, Talaromycosis marneffei, } \\
\text { Paracoccidioides, Burkholderia, cytomegalovirus, } \\
\text { Strongyloides }\end{array}$ \\
\hline T-cell depletion (anti-thymocyte globulin, alemtuzumab) & $\begin{array}{l}\text { Pneumocystis jirovecii, Streptococcus pneumoniae, } \\
\text { Mycobacterium TB, M. avium-intracellulare complex, and } \\
\text { other nontuberculous mycobacteria, Aspergillus and other } \\
\text { hyaline molds, Mucorales species, varicella-zoster, herpes } \\
\text { simplex, cytomegalovirus, Histoplasma capsulatum, } \\
\text { Coccidioides, Bartonella species, Toxoplasma gondii, } \\
\text { Cryptococcus neoformans, Nocardia, Legionella, } \\
\text { Strongyloides }\end{array}$ \\
\hline $\begin{array}{l}\text { Hypogammaglobulinemia (common variable } \\
\text { immunodeficiency, multiple myeloma, therapies that } \\
\text { target CD } 19 / 20 \text {, eg, rituximab) }\end{array}$ & $\begin{array}{l}\text { Respiratory viruses (influenza, respiratory syncytial virus, } \\
\text { human metapneumovirus, parainfluenza, adenovirus, } \\
\text { enterovirus), encapsulated bacteria (S pneumoniae, } \\
\text { Moraxella catarrhalis, Haemophilus influenzae, S aureus, } \\
\text { Capnocytophaga, Pasteurella multocida), cytomegalovirus, } \\
\text { Pneumocystis }\end{array}$ \\
\hline Calcineurin inhibitors (cyclosporine and tacrolimus) & $\begin{array}{l}\text { Legionella, Nocardia, Aspergillus and other hyaline molds, } \\
\text { Mucorales species, cytomegalovirus, endemic fungi }\end{array}$ \\
\hline $\begin{array}{l}\text { Antimetabolites (mycophenolate mofetil, azathioprine, } \\
\text { 6-MP, fludarabine) }\end{array}$ & $\begin{array}{l}\text { Cytomegalovirus, varicella, respiratory viruses (if B-cell } \\
\text { impairment), Legionella, Nocardia, Aspergillus and other } \\
\text { hyaline molds, Mucorales species, endemic fungi } \\
\text { (Pneumocystis post-fludarabine) }\end{array}$ \\
\hline $\begin{array}{l}\text { Mammalian target of rapamycin inhibitors (sirolimus, } \\
\text { everolimus) }\end{array}$ & Cryptococcus, Pneumocystis \\
\hline Tumor necrosis factor inhibitors & $\begin{array}{c}\text { Endemic fungi, Aspergillus, Mycobacterium (tuberculous and } \\
\text { nontuberculous), varicella-zoster, Nocardia, Pneumocystis }\end{array}$ \\
\hline Janus kinase signaling inhibitors (eg, ibrutinib, dasatinib) & Pneumocystis, mold, cytomegalovirus \\
\hline Corticosteroids & $\begin{array}{l}\text { Bacteria, esp. Pseudomonas aeruginosa, Pneumocystis } \\
\text { jirovecii, Staphylococcus aureus, mycobacteria, Aspergillus } \\
\text { and other hyaline molds, Mucorales species, } \\
\text { cytomegalovirus, varicella-zoster, herpes simplex, } \\
\text { Histoplasma capsulatum, Coccidioides, Cryptococcus } \\
\text { neoformans, Nocardia, Legionella, Strongyloides }\end{array}$ \\
\hline Other & $\begin{array}{l}\text { Natalizumab (Cryptococcus), vedolizumab (Mycobacterium } \\
\text { TB), tocilizumab (unknown), ustekinumab (theoretical } \\
\text { cytomegalovirus), secukinumab (theoretical mold), } \\
\text { eculizumab (Pseudomonas, mold), bortezomib (varicella- } \\
\text { zoster) }\end{array}$ \\
\hline
\end{tabular}

6-MP = 6-mercaptopurine

\section{E. Empirical Therapy: General Principles}

Question 8: What empirical therapy should be started in hospitalized patients with CAP who are immunocompromised?
We suggest that immunocompromised patients without any additional risk factors for drug-resistant bacteria can receive initial empirical therapy targeting only the core respiratory pathogens. 
TABLE 6 ] Microbiologic Studies That Can Be Done in Immunocompromised Patients Hospitalized With Community-Acquired Pneumonia

Studies
Sputum samples for bacterial, mycobacterial, and fungal stains and cultures
Comments: Sputum can be induced with inhaled isotonic or preferably hypertonic saline for certain pathogens
(eg, MTB, PCP) to avoid invasive procedures. Sputum samples can be tested by PCR for detection of MTB or
PCP

Nasopharyngeal swab with multiplex PCR for respiratory viruses

Comments: A negative nasopharyngeal PCR result does not rule out viral pneumonia. If the suspicion is high, perform the PCR on bronchoscopic samples. The finding of a virus by PCR does not rule out bacterial infection

Nasopharyngeal swab with multiplex PCR for atypical bacteria

Comments: Atypical pathogens such as Legionella, Chlamydophila, or Mycoplasma can also be identified in oropharyngeal samples

Nasal PCR for MRSA

Comments: Use in conjunction with a respiratory sample. A negative MRSA nasal PCR result, the absence of gram-positive cocci in clusters on Gram stain, and a negative MRSA respiratory culture make MRSA pneumonia extremely unlikely

Blood cultures times two (at least), 30 min apart

Comments: If there is a port or central line or PICC line, to define the presence of line infection, perform blood cultures from a peripheral vein and from the catheter lumens at the same time to calculate "time to positivity." The separation of samples over time improves bacterial detection in the case of intermittent bacteremia

Urinary antigen for Streptococcus pneumoniae

Comments: The recent administration of pneumococcal vaccine (within days) will produce a positive urinary antigen result for Streptococcus pneumoniae

Urinary antigen for Legionella

Comments: Detects only Legionella pneumophila serotype 1 . Other gram-negative bacteria may generate a false positive test result. Obtain respiratory samples for culture and PCR to detect other species of Legionella or serotypes if clinically indicated

Urinary antigen for Histoplasma capsulatum

Comments: Very useful for disseminated disease. Cross-reaction with blastomycosis

Serum antigen for Cryptococcus neoformans

Comments: A serum cryptococcal antigen test may produce a negative result for a patient with documented cryptococcal pneumonia

Serum galactomannan antigen

Comments: Aspergillus cell wall contains the polysaccharide galactomannan. Also elevated in Fusarium, Penicillium, blastomycosis, and histoplasmosis. False positive results may occur with IVIG, transfusions, and some $\beta$-lactam antibiotics

Serum 1,3- $\beta$-D-glucan

Comments: $\beta$-D-Glucan is a cell wall component of several fungi. It screens for Aspergillus species, Candida species, PCP, and other fungi. It does not detect mucormycosis. False positive results may occur with IVIG, hemodialysis with cellulose, albumin, infections with Pseudomonas, and some $\beta$-lactam antibiotics

Swabs of vesicular or ulcerated skin lesions for viral PCR and cultures

Comments: A positive PCR result for HSV or VZV from skin lesions is highly correlated with herpes or varicellazoster pneumonia

Biopsy of skin lesion for microbiology and pathology

Comments: Sample must be sent to microbiology and pathology for stains and cultures for viruses, bacteria, mycobacteria, fungi, and parasites

Viral load for CMV (PCR)

Comments: Obtain only if clinical suspicion is high. CMV reactivation is common in acute illness, and the presence of copies of CMV in plasma does not necessarily indicate invasive disease. On the other hand, the absence of viremia makes CMV pneumonitis less likely 


\begin{tabular}{l|c}
\hline Studies & References \\
\hline Viral load for adenovirus & 29 \\
\hline Comments: Obtain only if clinical suspicion is high. & 27 \\
Serology for histoplasmosis, coccidioidomycosis, and blastomycosis & Comments: Fungal serology is not generally recommended in immunosuppressed patients because they fail \\
$\quad$ to generate an adequate antibody response to infection &
\end{tabular}

CMV = cytomegalovirus; HSV = herpes simplex virus; IVIG = IV immunoglobulin; MTB = Mycobacterium TB; PCP = Pneumocystis jirovecii pneumonia; $\mathrm{PCR}=$ polymerase chain reaction; PICC = peripherally inserted central line catheter; VZV = varicella-zoster virus. See Table 1 legend for expansion of other abbreviation.

Although immunocompromised hosts may have unique immunologic risk and often more frequent nosocomial contact and antibiotic exposure, many immunocompromised patients admitted with CAP do not have any additional risk factors for drug-resistant bacteria (eg, methicillin-resistant Staphylococcus aureus [MRSA], Pseudomonas). For these patients, we suggest initial empirical antimicrobial therapy targeting the core respiratory pathogens described in Table 3. In this group of patients, the initial empirical antibacterial therapy would be the same as the initial empirical therapy for hospitalized patients with CAP who are not immunocompromised. ${ }^{1}$ Additional empirical treatment beyond the core respiratory pathogens should be considered according to the presence of risk factors for drug-resistant or opportunistic pathogens and is discussed in the sections below.

Question 9: In which patients with CAP who are immunocompromised should empirical therapy be extended beyond the core respiratory pathogens?

We suggest to extend empirical therapy beyond core respiratory pathogens when (1) risk factors for drugresistant organisms or opportunistic pathogens are present and (2) the delay in empirical antimicrobial therapy will place the patient at increased risk of mortality.

In addition to initial empirical treatment for core respiratory pathogens, we suggest broader initial coverage when the following factors are met: (1) A resistant bacterium or an opportunistic pathogen is suspected on the basis of the presence of risk factors from findings on history or physical examination, laboratory results, and/or imaging patterns; and (2) waiting for microbiologic identification of the suspected pathogen will significantly delay initiation of antimicrobial therapy and may increase the risk of mortality. Other considerations for extending initial empirical therapy beyond core pathogens include availability of point-of-care tests, severity of disease at presentation, and use of prophylactic therapy for a particular opportunistic pathogen.

The need for empirical therapy of opportunistic pathogens will continue to evolve as more point-of-care tests are developed for rapid diagnosis. Empirical therapy beyond core respiratory pathogens may not be necessary if the patient is clinically stable and the local setting allows for rapid microbiologic diagnostic tests.

Question 10: What role does the severity of pneumonia play in the selection of initial empirical therapy?

We suggest that the presence of severe pneumonia can be used as an indication to start empirical therapy for resistant gram-positive and gram-negative organisms, followed by rapid deescalation if no multidrug-resistant pathogen is identified.

Severity of illness is not by itself an accurate predictor of drug resistance or opportunistic infection in pneumonia. For example, Streptococcus pneumoniae is capable of causing life-threatening septic shock, whereas invasive pulmonary aspergillosis may present with an indolent, progressive course.

The impact of severe pneumonia on empirical therapy is the critical need to start early with an appropriate antimicrobial therapy, because an initial inadequate antibiotic spectrum has been identified as an independent risk factor for mortality in CAP. Given this circumstance, the presence of severe pneumonia or pneumonia requiring ICU care can be used as a threshold to start empirical therapy for resistant grampositive organisms (eg, MRSA) and resistant gramnegative organisms (eg, Pseudomonas).

\section{F. Empirical Therapy: Specific Pathogens}

Question 11: In which immunocompromised patients should the initial empirical therapy be extended to cover the possibility of CAP due to MRSA? 
We suggest that initial empirical therapy to cover for MRSA should be started in patients with a history of colonization or infection with MRSA in the previous 12 months.

In patients with a history of colonization or infection with MRSA in the previous 12 months, initial empirical therapy should cover the possibility of infection due to MRSA. There are other risk factors reported in the literature for MRSA infection such as prior antibiotic use, recent hospitalization, hemodialysis, or wound care, but if the local prevalence of MRSA is low these risk factors will each have a low positive predictive value and should not be used to trigger empirical anti-MRSA therapy. ${ }^{36-40}$ On the other hand, a single patient who accumulates many of these risk factors may have a high likelihood of CAP due to MRSA. Vancomycin or linezolid are the first line for initial empirical therapy. In regions with a high prevalence of MRSA, some members of the panel will start empirical anti-MRSA therapy in patients requiring ICU admission. A negative MRSA result by nasal polymerase chain reaction (PCR), absence of gram-positive cocci in clusters on Gram's staining, and a negative MRSA respiratory culture can be used to deescalate anti-MRSA therapy.

Question 12: In which immunocompromised patients should the initial empirical therapy be extended to cover the possibility of CAP due to drug-resistant gramnegative bacilli, including Pseudomonas aeruginosa?

We suggest that initial empirical therapy for immunocompromised patients should cover resistant gram-negative bacilli, including Pseudomonas aeruginosa, if there is a history of colonization or infection with a resistant gram-negative bacilli in the prior 12 months, previous hospitalization with exposure to broad-spectrum antibiotics, the presence of a tracheostomy, neutropenia, or a history of pulmonary comorbidity.

History of colonization or infection with a drug-resistant gram-negative bacillus in the previous 12 months, previous hospitalization with exposure to broadspectrum antibiotics, the presence of a tracheostomy, neutropenia, a history of pulmonary comorbidity (eg, cystic fibrosis, bronchiectasis, or recurrent exacerbations of COPD requiring glucocorticoid and antibiotic use) have been reported in the literature to increase the risk of resistant gram-negative bacilli. ${ }^{37-42}$ Patients with any of these risk factors should be considered for initial empirical therapy against resistant gram-negative bacilli including $P$ aeruginosa. $\beta$-Lactam antibiotics with activity against $P$ aeruginosa, such as piperacillintazobactam or a carbapenem, should be used as core therapy. However, ceftazidime, which has no reliable activity against $S$ pneumoniae, should not be used as monotherapy. ${ }^{43}$

Question 13: In which immunocompromised patients should the initial empirical therapy be extended to cover the possibility of CAP due to multidrug-resistant (MDR) gram-negative bacilli?

We suggest that in patients with a recent history of colonization or infection with MDR gram-negative bacilli, the initial empirical therapy should cover the possibility of infection due to the colonizing MDR gramnegative bacilli.

In patients with a recent history of colonization or infection with MDR gram-negative bacilli such as extended-spectrum $\beta$-lactamase-producing Enterobacteriaceae, carbapenemase-producing Enterobacteriaceae, MDR Pseudomonas, or MDR Acinetobacter, the initial empirical therapy should cover the possibility of infection with the colonizing MDR gram-negative bacilli. A knowledge of the local susceptibility profile for gram-negative bacilli and the most recent susceptibility profile of the colonizing MDR gram-negative bacilli will help in the selection of empirical therapy for these organisms with difficultto-treat resistance. For empirical therapy of MDR gram-negative bacilli, $\beta$-lactam antibiotics such as piperacillin-tazobactam or imipenem may have to be changed to newer $\beta$-lactam antibiotics that have better activity against some of the MDR bacteria. In these patients, consideration should be given to the addition of ceftazidime-avibactam, ceftolozane-tazobactam, or meropenem-vaborbactam. Adding a polymyxin such as colistin to a traditional $\beta$-lactam is a possibility when other agents are not available. In patients treated empirically with these broad-spectrum agents, we strongly emphasize an extended microbiologic workup and prompt deescalation of therapy if appropriate.

Question 14: In which immunocompromised patients should the initial empirical therapy be extended to cover the possibility of CAP due to Pneumocystis jirovecii pneumonia (PCP)?

We suggest initial empirical therapy should be extended to cover the possibility of PCP in patients with diffuse, bilateral, interstitial infiltrates or alveolar opacities and who are not receiving $P C P$ prophylaxis, and those who 
TABLE 7 ] Microbiologic Studies in BAL Fluid or Tranbronchial Lung Biopsy

\begin{tabular}{|c|c|}
\hline Study & Reference \\
\hline \multicolumn{2}{|l|}{ Bacterial Gram stain and culture } \\
\hline \multicolumn{2}{|l|}{$\begin{array}{l}\text { Comments: A negative stain and culture of MDR pathogens (eg, MRSA) can be used for deescalation of therapy } \\
\text { unless antibiotics have been given for }>48 \mathrm{~h}\end{array}$} \\
\hline \multicolumn{2}{|l|}{ MRSA PCR } \\
\hline $\begin{array}{l}\text { Comments: A negative PCR for MRSA can be used for deescalation of anti-MRSA therapy unless antibiotics } \\
\text { have been given for }>48 \mathrm{~h}\end{array}$ & 31 \\
\hline \multicolumn{2}{|l|}{ AFB stains and culture for tuberculous and nontuberculous mycobacteria } \\
\hline $\begin{array}{l}\text { Comments: If positive AFB stain, nucleic acid amplification (NAA) tests allows for rapid diagnosis. NAA test can } \\
\text { be performed if the AFB stain is negative and the suspicion of disease is high }\end{array}$ & 20 \\
\hline \multicolumn{2}{|l|}{ Nocardia stains and culture } \\
\hline \multicolumn{2}{|l|}{ Comments: AFB stain may be weakly positive } \\
\hline \multicolumn{2}{|l|}{ Fungal stains and culture } \\
\hline $\begin{array}{l}\text { Comments: Because Aspergillus can colonize the airways, positive stains or culture of Aspergillus species from } \\
\text { respiratory samples do not necessarily indicate disease }\end{array}$ & 27 \\
\hline \multicolumn{2}{|l|}{ PCP stains and PCR } \\
\hline $\begin{array}{l}\text { Comments: In patients with PCP, the sensitivity of staining is higher in HIV-infected patients when compared } \\
\text { with HIV-uninfected patients. A positive PCR may occur in patients colonized with PCP. In non-HIV patients, } \\
\text { a negative PCR can be used to discontinue anti-PCP therapy }\end{array}$ & 32 \\
\hline \multicolumn{2}{|l|}{ Respiratory viral panel with multiplex PCR } \\
\hline $\begin{array}{l}\text { Comments: Viruses can be detected in BAL by PCR in a patient with a negative nasopharyngeal swab PCR for } \\
\text { the same virus }\end{array}$ & 22,23 \\
\hline \multicolumn{2}{|l|}{ Atypical pathogens panel with multiplex PCR } \\
\hline \multicolumn{2}{|l|}{$\begin{array}{l}\text { Comments: A positive PCR is considered diagnostic for atypical pneumonia because pathogens such as } \\
\text { Legionella, Chlamydophila, or Mycoplasma rarely colonize the airway }\end{array}$} \\
\hline \multicolumn{2}{|l|}{ Galactomannan antigen } \\
\hline $\begin{array}{l}\text { Comments: The cell wall of Aspergillus contains the polysaccharide galactomannan. Other fungi that contain } \\
\text { galactomannan include Histoplasma capsulatum, Penicillium species, and Fusarium species. False positive } \\
\text { levels may occur in BAL samples with some } \beta \text {-lactam antibiotics }\end{array}$ & 27 \\
\hline \multicolumn{2}{|l|}{ Aspergillus PCR } \\
\hline $\begin{array}{l}\text { Comments: The high sensitivity of PCR produces a high negative predictive value, making the diagnosis } \\
\text { unlikely with a negative test }\end{array}$ & 27 \\
\hline \multicolumn{2}{|l|}{$(1,3)-\beta$-D-Glucan } \\
\hline $\begin{array}{l}\text { Comments: It is considered a poor screening tool for the diagnosis of invasive fungal infections because of its } \\
\text { low positive predictive value }\end{array}$ & 27 \\
\hline \multicolumn{2}{|l|}{ CMV PCR } \\
\hline $\begin{array}{l}\text { Comments: Quantitative PCR analysis in BAL fluid may help to differentiate between CMV pneumonia (high } \\
\text { viral load) vs CMV pulmonary shedding without pneumonia (low viral load), but cutoff levels are not defined }\end{array}$ & 33 \\
\hline \multicolumn{2}{|l|}{ Cellular analysis } \\
\hline $\begin{array}{l}\text { Comments: A predominantly inflammatory cellular pattern in the BAL with neutrophil pleocytosis can be used } \\
\text { as a predictor of bacterial etiology }\end{array}$ & 34,35 \\
\hline \multicolumn{2}{|l|}{ Histopathology } \\
\hline $\begin{array}{l}\text { Comments: Routine hematoxylin and eosin staining, special stains, and culture for viruses, bacteria, } \\
\text { mycobacteria, fungi, and parasites }\end{array}$ & \\
\hline
\end{tabular}

are either (1) HIV hosts who is newly diagnosed, or not on antiretroviral therapy, or with CD4 counts less than $200 \mathrm{cells} / \mu L$ (or a percentage lower than 14\%) or (2) nonHIV hosts with severely impaired cell-mediated immunity (eg, taking glucocorticoids with cytotoxic agents).
In these patients we suggest the addition of trimethoprim-sulfamethoxazole (TMP-SMX) to the initial regimen. The recommended dosage for TMPSMX is 15 to $20 \mathrm{mg} / \mathrm{kg} / \mathrm{d}$ of the trimethoprim component orally or IV, given in three or four divided 
doses. $^{44}$ The dose of TMP-SMX is the same for PCP in the HIV-infected patient and PCP in the immunocompromised non-HIV-infected patient. Adjunctive glucocorticoids are recommended for HIVinfected patients with room air $\mathrm{PaO}_{2}<70 \mathrm{~mm} \mathrm{Hg}$ and/ or an alveolar-arterial (A-a) oxygen gradient $\geq$ $35 \mathrm{~mm} \mathrm{Hg} .{ }^{44}$ Corticosteroids are not beneficial in HIVnegative patients with PCP. ${ }^{45}$

Question 15: In which immunocompromised patients should the initial empirical therapy be extended to cover the possibility of CAP due to Aspergillus?

We suggest that empirical therapy should cover the possibility of pneumonia due to filamentous fungi such as Aspergillus in patients with cancer and chemotherapy with severe and prolonged neutropenia and a radiographic nodular pattern surrounded by a halo of ground-glass attenuation and/or cavitation.

Voriconazole is considered the first-line treatment for patients with documented invasive aspergillosis, but we do not suggest empirical voriconazole because these patients are also at risk for other filamentous fungi resistant to voriconazole (eg, those causing mucormycosis). ${ }^{46}$ In these patients we suggest empirical therapy with liposomal amphotericin at dosages of 5 to $7.5 \mathrm{mg} / \mathrm{kg}$ daily. In patients intolerant to amphotericin, empirical therapy with isavuconazole at an initial dosage of $200 \mathrm{mg}$ every $8 \mathrm{~h}$ can be used as an alternative. ${ }^{47}$

Patients treated with tumor necrosis factor (TNF) inhibitors, such as etanercept, infliximab, or adalimumab, are also at risk of fungal pneumonia. ${ }^{11,12}$ In these patients we suggest an aggressive diagnostic workup, and treat if a fungus is identified. In the treatment of these patients it is important to discontinue the use of the anti-TNF drug at the time of diagnosis of pneumonia to improve the level of immunity of the patient.

Question 16: In which immunocompromised patients should the initial empirical therapy be extended to cover the possibility of CAP due to Mucorales?

We suggest that empirical therapy should cover the possibility of pneumonia due to filamentous fungi such as Mucorales in patients with cancer and chemotherapy with severe and prolonged neutropenia and a radiographic nodular pattern, or a reverse halo sign, or pleural effusion.

Empirical therapy for Mucorales is especially important when fungal infection is suspected in a patient receiving voriconazole antifungal prophylaxis. In these patients we suggest liposomal amphotericin as part of the initial empirical regimen at dosages of 5 to $7.5 \mathrm{mg} / \mathrm{kg}$ daily. ${ }^{48}$ In patients intolerant to amphotericin, empirical therapy with isavuconazole at an initial dosage of $200 \mathrm{mg}$ every $8 \mathrm{~h}$ can be used as an alternative. ${ }^{47}$ Voriconazole does not cover mucormycosis, and therefore it is not suggested as initial empirical therapy.

Question 17: In which immunocompromised patients should the initial empirical therapy be extended to cover the possibility of CAP due to Nocardia?

We suggest that empirical therapy should include the possibility of Nocardia infection in patients with heart, lung, liver, or hematopoietic stem cell transplant with pneumonia and evidence for a lung or brain abscess, and who have not been receiving prophylaxis with TMP-SMX.

In these patients we suggest the addition of TMP-SMX to the initial empirical therapy at a dosage of $15 \mathrm{mg} / \mathrm{kg} /$ $\mathrm{d}$ of the trimethoprim component IV in three or four divided doses. ${ }^{49}$ Resistance of Nocardia species to TMPSMX is a rare event. ${ }^{50}$ If TMP-SMX is contraindicated, linezolid also has excellent activity and can be considered for empirical therapy until susceptibilities are known. ${ }^{50}$ If initial treatment already contains a drug with activity against Nocardia species (eg, linezolid or imipenem), empirical addition of TMP-SMX is not requested. However, TMP-SMX is the drug of choice for definite treatment.

Question 18: In which immunocompromised patients should the initial empirical therapy be extended to cover the possibility of CAP due to varicella-zoster virus?

We suggest that empirical therapy be extended to cover the possibility of CAP due to varicella-zoster virus in patients with bilateral reticulonodular infiltrates who also have a vesicular rash.

In these patients we suggest the addition of IV acyclovir, 10 to $15 \mathrm{mg} / \mathrm{kg}$ IV every $8 \mathrm{~h}$, to the initial empirical regimen. $^{51}$

Question 19: In which immunocompromised patients should the initial empirical therapy be extended to cover the possibility of CAP due to cytomegalovirus?

We suggest that empirical therapy be extended to cover the possibility of CAP due to cytomegalovirus in patients with bilateral interstitial pneumonia after a recent lung transplant or hematopoietic stem cell transplant. 
In these patients we suggest the addition of ganciclovir to the initial regimen at a dosage of $5 \mathrm{mg} / \mathrm{kg}$ IV every 12 $\mathrm{h}$, with dose adjustment for renal dysfunction. ${ }^{52}$

Elevated plasma cytomegalovirus (CMV) viral loads are frequent in patients with CMV pneumonitis, but this finding alone is not sufficient for diagnosis. ${ }^{53}$ In lung transplant recipients, CMV PCR viral load in BAL is a superior diagnostic tool than plasma CMV viral load. ${ }^{54}$

Question 20: In which immunocompromised patients should the initial empirical therapy be extended to cover the possibility of CAP due to Mycobacterium tuberculosis?

We suggest not to start empirical therapy to cover the possibility of CAP due to Mycobacterium TB.

Pulmonary infections due to mycobacteria, such as TB, are common in patients treated with TNF inhibitors and patients with long-term high-dose steroids. ${ }^{11}$ But in the case of suspected mycobacterial pneumonia we do not suggest treating the patient with empirical therapy. We suggest carrying out the indicated microbiologic studies and beginning treatment once the pathogen has been identified. We think that in these patients the risk-tobenefit ratio of expanding empirical therapy with multiple mycobacterial drugs, vs waiting to define which patients have a mycobacterial infection, is in favor of waiting for microbiologic results and treating them specifically.

An exception to this approach would be in patients with HIV infection with a history of recent exposure, who have other clinical findings and radiographic features compatible with TB infection, and who present with severe CAP. In these patients we will start empirical therapy for TB pending microbiologic workup. ${ }^{44}$

Question 21: In which immunocompromised patients should the initial empirical therapy be extended to cover the possibility of CAP due to parasites?

We suggest not to start empirical therapy to cover CAP due to parasites.

Parasites that can produce CAP in the immunocompromised host include Strongyloides stercoralis and Toxoplasma gondii. ${ }^{55,56}$

Pneumonia in patients with Strongyloides hyperinfection syndrome may be due to invasion of lung tissue by the filariform larvae or with gram-negative bacteremia secondary to seeding of the blood from the GI tract. Patients at risk of Strongyloides hyperinfection syndrome include those with solid organ transplantation, hematopoietic stem cell transplantation, or patients with high and prolonged dosages of corticosteroids (eg, prednisone $\geq 20 \mathrm{mg} / \mathrm{d}$, or its equivalent, for longer than 1 month) in combination with cytotoxic agents. Patients receiving this type of immune-suppressing therapy, and also those with secondary bacteremias, may not have an elevated eosinophil count suggesting a parasitic infection. Therapy with ivermectin is recommended for patients with hyperinfection syndrome. ${ }^{55}$

Toxoplasma pneumonia occurs due to reactivation of latent infection in (1) patients with HIV infection that is newly diagnosed, and not undergoing antiretroviral therapy or with CD4 counts less than 100 cells/ $\mu \mathrm{L}$; or (2) patients with defects in cell-mediated immunity due to high and prolonged doses of corticosteroids in combination with cytotoxic agents. Therapy with pyrimethamine and sulfadiazine is recommended for patients with Toxoplasma pneumonia. ${ }^{44}$

We think that in these patients the risk-to-benefit ratio of expanding empirical therapy for parasitic infections, or waiting to define which patients have a parasitic infection, favors waiting for microbiologic results and treat only the patients with a proven parasitic infection.

\section{Discussion}

In this document we have developed general suggestions for the initial treatment of the immunocompromised patient who arrives at the hospital with pneumonia. Despite our suggestions of empirical therapy for specific pathogens in specific situations, we stress the importance of making a concerted effort to establish a rapid and accurate etiologic diagnosis and to deescalate complex therapies once a presumptive pathogen is properly ruled out. It is also important to consider local susceptibility patterns when selecting empirical therapy. The participants do suggest that, if evidence supports the presence of infections that require highly specialized management (eg, cytomegalovirus or Mucorales), after initial therapy is begun, prompt transfer to a tertiary care facility should be strongly considered. Transfer to a specialized center may not be necessary if experienced pulmonary and infectious disease specialists are available to participate in management.

An important weakness of this document is the simplification of heterogeneous conditions that affect different arms of the immune system into a single group of immunocompromised patients with CAP. Another limitation is that we were not able to provide references 
that appropriately support several of our suggestions; hence we need to emphasize that the suggestions offered in this consensus are based primarily on expert opinion.

In conclusion, we have developed general suggestions for the initial treatment of immunocompromised patients hospitalized with pneumonia. When possible, the care of these patients should be carried out by a multidisciplinary group of specialists. Because immunocompromised patients have been excluded from prospective randomized studies of CAP treatment, there is an urgent need to generate scientific evidence in this field.

\section{Acknowledgments}

Author contributions: Development of first round of Delphi questions and draft of the initial manuscript: J. A. R., D. M. M, S. E. E., C. D. C., K. A. C., and C. A. H. Development of all other rounds of Delphi questions and subsequent versions of the manuscript: all authors. Final version of the manuscript: J. A. R. and approved by all authors.

\section{Financial/nonfinancial disclosures: None declared.}

Role of sponsors: The sponsor had no role in the design of the study, the collection and analysis of the data, or the preparation of the manuscript.

Additional information: The e-Appendix can be found in the Supplemental Materials section of the online article.

\section{References}

1. Metlay JP, Waterer GW, Long AC, et al. Diagnosis and treatment of adults with community-acquired pneumonia: an official clinical practice guideline of the American Thoracic Society and Infectious Diseases Society of America. Am J Respir Crit Care Med. 2019;200(7):e45-e67.

2. Woodhead M, Blasi F, Ewig S, et al. Guidelines for the management of adult lower respiratory tract infections: full version. Clin Microbiol Infect. 2011;17(suppl 6):E1-E59.

3. Lim WS, Baudouin SV, George RC, et al. BTS guidelines for the management of community acquired pneumonia in adults: update 2009. Thorax. 2009;64(suppl 3):iii1-iii55.

4. Harpaz R, Dahl RM, Dooling KL. Prevalence of immunosuppression among US adults, 2013. JAMA. 2016;316(23):2547-2548.

5. Di Pasquale MF, Sotgiu G, Gramegna A, et al. Prevalence and etiology of community-acquired pneumonia in immunocompromised patients. Clin Infect Dis. 2019;68(9):14821493.

6. Sousa D, Justo I, Domínguez A, et al. Community-acquired pneumonia in immunocompromised older patients: incidence, causative organisms and outcome. Clin Microbiol Infect. 2013;19(2):187-192.

7. Jain S, Self WH, Wunderink RG, et al. Community-acquired pneumonia requiring hospitalization among U.S. adults. N Engl J Med. 2015;373(5):415-427.

8. Huang L, Crothers K. HIV-associated opportunistic pneumonias. Respirology. 2009;14(4):474-485.

9. Stuck AE, Minder CE, Frey FJ. Risk of infectious complications in patients taking glucocorticosteroids. Rev Infect Dis. 1989;11(6):954963.

10. Sepkowitz KA, Brown AE, Armstrong D. Pneumocystis carinii pneumonia without acquired immunodeficiency syndrome: more patients, same risk. Arch Intern Med. 1995;155(11):1125-1128.

11. Davis BP, Ballas ZK. Biologic response modifiers: indications, implications, and insights. J Allergy Clin Immunol. 2017;139(5): 1445-1456.
12. Baddley JW, Cantini F, Goletti D, et al. ESCMID Study Group for Infections in Compromised Hosts (ESGICH) consensus document on the safety of targeted and biological therapies: an infectious diseases perspective (soluble immune effector molecules [I]: antitumor necrosis factor- $\alpha$ agents). Clin Microbiol Infect. 2018;24(suppl 2):S10-S20.

13. Wolfe F, Caplan L, Michaud K. Treatment for rheumatoid arthritis and the risk of hospitalization for pneumonia: associations with prednisone, disease-modifying antirheumatic drugs, and anti-tumor necrosis factor therapy. Arthritis Rheum. 2006;54(2):628-634.

14. Sanders KM, Marras TK, Chan CK. Pneumonia severity index in the immunocompromised. Can Respir J. 2006;13(2):89-93.

15. Carrabba M, Zarantonello M, Bonara P, et al. Severity assessment of healthcare-associated pneumonia and pneumonia in immunosuppression. Eur Respir J. 2012;40(5):1201-1210.

16. Gonzalez C, Johnson T, Rolston K, Merriman K, Warneke C, Evans S. Predicting pneumonia mortality using CURB-65, PSI, and patient characteristics in patients presenting to the emergency department of a comprehensive cancer center. Cancer Med. 2014;3(4):962-970.

17. Majumdar SR, Eurich DT, Gamble JM, Senthilselvan A, Marrie TJ. Oxygen saturations less than $92 \%$ are associated with major adverse events in outpatients with pneumonia: a population-based cohort study. Clin Infect Dis. 2011;52(3):325-331.

18. Serra MC, Cervera C, Pumarola T, et al. Virological diagnosis in community-acquired pneumonia in immunocompromised patients. Eur Respir J. 2008;31(3):618-624.

19. Buchan BW, Ledeboer NA. Emerging technologies for the clinical microbiology laboratory. Clin Microbiol Rev. 2014;27(4):783-822.

20. Lewinsohn DM, Leonard MK, LoBue PA, et al. Official American Thoracic Society/Infectious Diseases Society of America/Centers for Disease Control and Prevention clinical practice guidelines: diagnosis of tuberculosis in adults and children. Clin Infect Dis. 2017;64(2):111-115.

21. Fujisawa T, Suda T, Matsuda H, et al. Real-time PCR is more specific than conventional PCR for induced sputum diagnosis of Pneumocystis pneumonia in immunocompromised patients without HIV infection. Respirology. 2009;14(2):203-209.

22. Choi SH, Hong SB, Ko GB, et al. Viral infection in patients with severe pneumonia requiring intensive care unit admission. Am J Respir Crit Care Med. 2012;186(4):325-332.

23. Lachant DJ, Croft DP, McGrane Minton H, Prasad P, Kottmann RM. Nasopharyngeal viral PCR in immunosuppressed patients and its association with virus detection in bronchoalveolar lavage by PCR. Respirology. 2017;22(6):1205-1211.

24. Raad I, Hanna HA, Alakech B, Chatzinikolaou I, Johnson MM, Tarrand J. Differential time to positivity: a useful method for diagnosing catheter-related bloodstream infections. Ann Intern Med. 2004;140(1):18-25.

25. Lamy B, Dargère $S$, Arendrup MC, Parienti JJ, Tattevin P. How to optimize the use of blood cultures for the diagnosis of bloodstream infections? A state-of-the-art. Front Microbiol. 2016;7:697.

26. Como J, Moffa MA, Bhanot N, et al. Potential false-positive urine Legionella enzyme immunoassay test results. Eur J Clin Microbiol Infect Dis. 2019;38(7):1377-1382.

27. Hage CA, Carmona EM, Epelbaum O, et al. Microbiological laboratory testing in the diagnosis of fungal infections in pulmonary and critical care practice: an official American Thoracic Society clinical practice guideline. Am J Respir Crit Care Med. 2019;200(5): 535-550.

28. Kraft CS, Armstrong WS, Caliendo AM. Interpreting quantitative cytomegalovirus DNA testing: understanding the laboratory perspective. Clin Infect Dis. 2012;54(12):1793-1797.

29. Matthes-Martin S, Feuchtinger T, Shaw PJ, et al. Fourth European Conference on Infections in Leukemia. European guidelines for diagnosis and treatment of adenovirus infection in leukemia and stem cell transplantation: summary of ECIL-4 (2011). Transpl Infect Dis. 2012;14(6):555-563. 
30. Bauer PR, Chevret S, Yadav H, et al. Diagnosis and outcome of acute respiratory failure in immunocompromised patients after bronchoscopy. Eur Respir J. 2019;54(1):1802442.

31. Paonessa JR, Shah RD, Pickens CI, et al. Rapid detection of methicillin-resistant Staphylococcus aureus in BAL: a pilot randomized controlled trial. Chest. 2019;155(5):999-1007.

32. Azoulay É, Bergeron A, Chevret S, Bele N, Schlemmer B, Menotti J. Polymerase chain reaction for diagnosing pneumocystis pneumonia in non-HIV immunocompromised patients with pulmonary infiltrates. Chest. 2009;135(3):655-661.

33. Ljungman P, Boeckh M, Hirsch $\mathrm{HH}$, et al. Disease Definitions Working Group of the Cytomegalovirus Drug Development Forum. Definitions of cytomegalovirus infection and disease in transplant patients for use in clinical trials. Clin Infect Dis. 2017;64(1):87-91.

34. Stolz D, Stulz A, Müller B, Gratwohl A, Tamm M. BAL neutrophils, serum procalcitonin, and C-reactive protein to predict bacterial infection in the immunocompromised host. Chest. 2007;132(2):504-514.

35. Choi S-H, Hong S-B, Hong H-L, et al. Usefulness of cellular analysis of bronchoalveolar lavage fluid for predicting the etiology of pneumonia in critically ill patients. PLoS One. 2014;9(5):e97346.

36. Aliberti S, Reyes LF, Faverio P, et al. GLIMP Investigators. Global initiative for met[h]icillin-resistant Staphylococcus aureus pneumonia (GLIMP): an international, observational cohort study. Lancet Infect Dis. 2016;16(12):1364-1376.

37. Webb BJ, Dascomb K, Stenehjem E, Dean N. Predicting risk of drugresistant organisms in pneumonia: moving beyond the HCAP model. Respir Med. 2015;109(1):1-10.

38. Shorr AF, Zilberberg MD, Reichley R, et al. Validation of a clinical score for assessing the risk of resistant pathogens in patients with pneumonia presenting to the emergency department. Clin Infect Dis. 2012;54(2):193-198.

39. Aliberti S, Cilloniz C, Chalmers JD, et al. Multidrug-resistant pathogens in hospitalised patients coming from the community with pneumonia: a European perspective. Thorax. 2013;68(11):997-999.

40. Shindo Y, Ito R, Kobayashi D, et al. Risk factors for drug-resistant pathogens in community-acquired and healthcare-associated pneumonia. Am J Respir Crit Care Med. 2013;188(8):985-995.

41. Villafuerte D, Aliberti S, Soni NJ, et al. GLIMP Investigators. Prevalence and risk factors for Enterobacteriaceae in patients hospitalized with community-acquired pneumonia. Respirology. 2020;25(5):543-551.

42. Restrepo MI, Babu BL, Reyes LF, et al. Burden and risk factors for Pseudomonas aeruginosa community-acquired pneumonia: a multinational point prevalence study of hospitalised patients. Eur Respir J. 2018;52(2):1701190.

43. Barry AL, Brown SD, Novic WJ. In vitro activities of cefotaxime, ceftriaxone, ceftazidime, cefpirome and penicillin against
Streptococcus pneumoniae isolates. Antimicrob Agents Chemother. 1995;39(10):2193-2196.

44. Panel on Opportunistic Infections in Adults and Adolescents with HIV. AIDSinfo: Guidelines for the Prevention and Treatment of Opportunistic Infections in HIV-Infected Adults and Adolescents. http://aidsinfo.nih.gov/contentfiles/lvguidelines/adult_oi.pdf. Accessed July 7, 2020.

45. Wieruszewski PM, Barreto JN, Frazee E, et al. Early corticosteroids for Pneumocystis pneumonia in adults without HIV are not associated with better outcome. Chest. 2018;154(3):636-644.

46. Centers for Disease Control and Prevention. Fungal Diseases: Information for Healthcare Professionals About Mucormycosis. https://www.cdc.gov/fungal/diseases/mucormycosis/healthprofessionals.html\#twenty-six. Accessed July 7, 2020.

47. Marty FM, Ostrosky-Zeichner L, Cornely OA, et al. Isavuconazole treatment for mucormycosis: a single-arm open-label trial and casecontrol analysis. Lancet Infect Dis. 2016;16(7):828-837.

48. Spellberg B, Walsh TJ, Kontoyiannis DP, Edwards J Jr, Ibrahim AS. Recent advances in the management of mucormycosis: from bench to bedside. Clin Infect Dis. 2009;48(12):1743-1751.

49. Restrepo A, Clark NM; Infectious Diseases Community of Practice of the American Society of Transplantation. Nocardia infections in solid organ transplantation: guidelines from the Infectious Diseases Community of Practice of the American Society of Transplantation. Clin Transplant. 2019;33(9):e13509.

50. Schlaberg R, Fisher MA, Hanson KE. Susceptibility profiles of Nocardia isolates based on current taxonomy. Antimicrob Agents Chemother. 2014;58(2):795-800.

51. Mirouse A, Vignon P, Piron P, et al. Severe varicella-zoster virus pneumonia: a multicenter cohort study. Crit Care. 2017;21(1):137.

52. Machado CM, Dulley FL, Boas LS, et al. CMV pneumonia in allogeneic BMT recipients undergoing early treatment of preemptive ganciclovir therapy. Bone Marrow Transplant. 2000;26(4): 413-417.

53. Travi G, Pergam SA. Cytomegalovirus pneumonia in hematopoietic stem cell recipients. J Intensive Care Med. 2014;29(4):200-212.

54. Lodding IP, Schultz HH, Jensen JU, et al. Cytomegalovirus viral load in bronchoalveolar lavage to diagnose lung transplant associated CMV pneumonia. Transplantation. 2018;102(2):326-332.

55. Keiser PB, Nutman TB. Strongyloides stercoralis in the immunocompromised population. Clin Microbiol Rev. 2004;17(1): 208-217.

56. Patrat-Delon S, Gangneux JP, Lavoué S, et al. Correlation of parasite load determined by quantitative PCR to clinical outcome in a heart transplant patient with disseminated toxoplasmosis. J Clin Microbiol. 2010;48(7):2541-2545. 